\title{
Viruses carried to soil by irrigation can be aerosolized later during windy spells
}

\author{
Guillaume Girardin $^{1}$ - Pierre Renault ${ }^{1}$ (D) Fabienne Bon ${ }^{2} \cdot$ Line Capowiez $^{1}$ • \\ Joël Chadoeuf $^{3}$ - Camille Krawczyk $^{1}$ - Dominique Courault ${ }^{1}$
}

Accepted: 1 September 2016/Published online: 12 October 2016

(C) The Author(s) 2016. This article is published with open access at Springerlink.com

\begin{abstract}
Reclaiming domestic wastewaters for irrigation helps to meet increasing water needs, to reduce discharge to conventional waters, and to fertilize soils. Unfortunately, it also contaminates crop and soil with human enteric pathogens. However, partial aerosolization of pathogens deposited on soil surface during windy periods has never been studied. Here, we investigated this putative aerosolization of pathogens from soil surface during windy periods by using murine mengoviruses, a surrogate of human enteric viruses, and assess the impact of environmental conditions on this phenomenon. Wind tunnel experiments were carried out on virus-contaminated plots submitted to various wind, soil surface moisture, and water types. Aerosolized viruses were trapped by impingers for RT-qPCR quantification. Virus concentrations were corrected for partial virus trapping efficiency and reaerosolization. A mathematical model was devised for one or more virus groups, characterized by their number of viruses and their kinetic aerosolization coefficient. The model was fitted to real trial data and used to generate numerical experiments to study the model estimators. We showed that 1 to $15 \%$ of viruses carried to soil were aerosolized, of which 11 to $89 \%$ during the first $0.5 \mathrm{~h}$. The viruses fell into
\end{abstract}

The original version of this article was revised due to a retrospective Open Access order. The erratum is available under DOI 10.1007/s13593-0170451-9.

Guillaume Girardin and Pierre Renault contributed equally to this work and are co-first authors.

Pierre Renault

pierre.renault@avignon.inra.fr

1 UMR 1114 EMMAH, INRA, 84000 Avignon, France

2 UMR 1347 Agroécologie, Université de Bourgogne-Franche Comté, 21000 Dijon, France

3 UR 1052 Statistics, INRA, 84000 Avignon, France two groups: a group that get aerosolized near instantaneously and a group that get aerosolized gradually. The range of kinetic coefficients of aerosolization of the gradually aerosolized group accounted for $90 \%$ of viruses of this group aerosolized after $0.5-10.6$ days. The size of this group increased with wind speed, decreased with soil warming, and increased with organic content of spray water. This first study on virus aerosolization shows that aerosolization cannot be neglected both in terms of quantities and speeds. Combined with virus stability in air, we anticipate our model to help policymakers refine regulations and standards governing wastewater reuse in irrigation.

Keywords Wastewater reuse · Irrigation · Enteric viruses · Virus aerosolization $\cdot$ Environmental context

\section{Introduction}

The world is facing increasing water scarcity due to population growth, urbanization, global warming, and diversification of water uses (Van der Bruggen 2010), while the quality of existing conventional water resources is declining due to discharge of inadequately treated wastewater (Prevost et al. 2015). In this context, wastewater reuse for crop irrigation is emerging as an attractive resource alternative to conventional water while decreasing discharges into water bodies and fertilizing cropland (Jiménez et al. 2010). However, the process also carries health risks due to the presence of chemicals and human pathogens, including enteric viruses, in effluent from activated sludge secondary treatments (Pachepsky et al. 2011). Enteric viruses are often reported as causes of waterborne and foodborne disease outbreaks (Rodríguez-Lázaro et al. 2012), and the Codex Alimentarius Commission cites noroviruses and hepatitis A viruses as the most common culprits (C.A.C. 2012).

Irrigation can deposit human enteric viruses in treated wastewater onto the surface of the soil and plant leaves or 
stems. Environmental viral contaminations have been reported through soil-to-aquifer dissemination (Gerba 1999). Noroviruses and hepatitis A viruses can be internalized in the roots and disseminate to edible portions of plants without being inactivated (DiCaprio et al. 2015). Viral adhesion at the surface of plant leaves or stems followed by internalization has also been reported (Esseili et al. 2012). Airborne outbreaks of viral enteric diseases have been reported to occur in indoor environments (Nazaroff 2011), but the impact of aerosolization of viruses in outdoor environments has never been investigated, including during/after wastewater irrigation. Human enteric viruses have been detected in outdoor air in the vicinity of wastewater treatment plants during windy spells (Masclaux et al. 2014) and irrigation with wastewater (Teltsch and Katzenelson 1978). Thus, if the dynamics of virus aerosolization, air transport, and inactivation can be quantified, quantitative microbial risk assessment models already proposed for airborne contamination can be used for farms reclaiming wastewater (Mara et al. 2007).

New improved molecular methods can now detect and quantify viruses in environmental samples (Mattison and Bidawid 2009). A perfect method for bioaerosol collection is not yet available, despite the development of various biocollectors (Verreault et al. 2008). Impingers are still imperfect due to incomplete virus trapping and viral reaerosolization (Dart and Thornburg 2008; Lin et al. 1997). The collection efficiency of impingers is affected by geometry, air flow, height and nature of the trapping solution, and size and water repellency of the particles (Lin et al. 1997). AGI-4 impingers have been used to trap Bacillus cereus spores (Lin et al. 1997) and large T1 bacteriophages (Harstad 1965).

The aim of this study was to check whether viruses carried to soil by irrigation do get aerosolized and, if so, to assess total amounts of viruses aerosolized and their kinetics of aerosolization according to environmental conditions. For this purpose, murine mengoviruses were applied to soil by irrigation, and experiments were carried out by using the wind tunnel technique (Loubet et al. 1999) with AGI-4 impingers to trap the viruses. We devised a mathematical model describing aerosolization and used it to estimate total amounts of viruses aerosolized and their kinetic coefficients of aerosolization. We then analyzed the variations in these estimates according to wind speed, soil surface moisture and temperature, and chemical composition of the irrigation water.

\section{Materials and methods}

\subsection{Virus, soil, and irrigation water}

Cytopathic murine mengovirus strain MC0 (Martin et al. 1996), as surrogate of human enteric viruses (Sano et al.
2015), was kindly provided by Prof. A. Bosch (University of Barcelona). Mengoviruses were propagated on buffalo green monkey kidney (BGMK) cells in Dulbecco's modified Eagle medium (Gibcoß) supplemented with $10 \%(v / v)$ fetal calf serum, $5 \%(v / v)$ nonessential amino acids (Gibcoß), and $1 \%$ antifungal-antibiotic (Gibco ${ }^{\circledR}$, penicillin streptomycin and Fungizone ${ }^{\circledR}$ ) under $9 \% \mathrm{CO}_{2}$ at $37^{\circ} \mathrm{C}$. BGMK cells at $90 \%$ confluence in a $175-\mathrm{cm}^{2}$ flask were infected for $1 \mathrm{~h}$ with $10^{5}$ mengovirus genomic copies (gc). After 3 days, the culture medium was recovered, sonicated for $10 \times 15$-s cycles and centrifuged for $5 \mathrm{~min}$ at $2700 \times \mathrm{g}$ at $4{ }^{\circ} \mathrm{C}$. The supernatant containing viruses (approx. $10^{8} \mathrm{gc} \mathrm{mL}^{-1}$ ) was collected, and aliquots of $35-40 \mathrm{~mL}$ were stored at $-21{ }^{\circ} \mathrm{C}$. For each wind tunnel experiment, three aliquots were thawed at room temperature for $1 \mathrm{~h} ; 100 \mathrm{~mL}$ was then diluted with demineralized water or wastewater to obtain $1 \mathrm{~L}$ of viral suspension. This suspension was spread by using a sprayer. Mengoviruses were quantified by RT-qPCR on $60 \mu \mathrm{L}$ of viral RNA extracted from $140 \mu \mathrm{L}$ of trapping solution as per the manufacturer's instructions (QIAamp ${ }^{\circledR}$ Viral RNA Kit (Qiagen)). RT-qPCR was performed by using the RNA UltraSense ${ }^{\circledR}$ One-Step Quantitative RT-PCR System Kit (Life Technologies ${ }^{\circledR}$ ) by using the probe and primers described by Pinto et al. (2009). For each viral quantification, one to nine RT-qPCR replicates were performed.

Experiments were led on a calcareous cambisol (FAO classification) from the INRA station $\left(43^{\circ} 92^{\prime} \mathrm{N}, 4^{\circ} 88^{\prime} \mathrm{E}\right)$ near Avignon. Average annual on-station rainfall was $687 \mathrm{~mm}$ for the period 1989-2014. The soil had been grassed since 2011. On March 2014, it was tilled first to a depth of $15 \mathrm{~cm}$ by using disk harrows and then to a depth of about $10 \mathrm{~cm}$ by using a rotary tiller (twice) followed by a power harrow. The soil consisted mainly of 5-40-mm diameter aggregates/clods. For each experiment, the $10-\mathrm{cm}$ top layer contaminated by the previous experiment was replaced with soil from the same field. Soil properties of the $0-10-\mathrm{cm}$ layer were $362 \mathrm{~g} \mathrm{~kg}^{-1}$ $\mathrm{CaCO}_{3}$, and after decarbonation, $238 \mathrm{~g} \mathrm{~kg}^{-1}$ clay, $227 \mathrm{~g} \mathrm{~kg}^{-1}$ silt, $169 \mathrm{~g} \mathrm{~kg}^{-1}$ sand, $14.3 \mathrm{~g} \mathrm{~kg}^{-1}$ organic $\mathrm{C}, 1.35 \mathrm{~g} \mathrm{~kg}^{-1}$ total $\mathrm{N}, 1.45 \mathrm{mg} \mathrm{kg}^{-1} \mathrm{~N}-\mathrm{NH}_{4}{ }^{+}$, and $6.89 \mathrm{mg} \mathrm{kg}^{-1} \mathrm{~N}^{-\mathrm{NO}_{3}}{ }^{-}$. Soil $\mathrm{pH}$ (water) was 8.38. The concentrations of $\mathrm{Ca}^{2+}, \mathrm{Mg}^{2+}, \mathrm{K}^{+}$, and $\mathrm{Na}^{+}$extracted by water were $114,8.9,65.3$, and $10.5 \mathrm{mg} \mathrm{kg}^{-1}$ soil, respectively.

Two types of water were used to spread murine mengoviruses on the soil surface: ultrapure water and treated wastewater reclaimed for agricultural irrigation near Clermont-Ferrand (France). Wastewater samples were successively autoclaved three times at $12-20$-h intervals. They contained $10 \mathrm{mg} \mathrm{L}^{-1}$ of suspended matter and $24.1 \mathrm{mg} \mathrm{L}^{-1}$ of organic $\mathrm{C}$. They also contained $\mathrm{Ca}^{2+}\left(93.6 \mathrm{mg} \mathrm{L}^{-1}\right), \mathrm{Mg}^{2+}$ (17.5 mg L$\left.{ }^{-1}\right), \mathrm{K}^{+}\left(34.4 \mathrm{mg} \mathrm{L}^{-1}\right), \mathrm{Na}^{+}\left(87.5 \mathrm{mg} \mathrm{L}^{-1}\right), \mathrm{NH}_{4}^{+}$ (4.89 $\left.\mathrm{mg} \mathrm{N} \mathrm{L}^{-1}\right), \mathrm{NO}_{3}^{-}\left(0.6 \mathrm{mg} \mathrm{N} \mathrm{L}^{-1}\right)$, and $\mathrm{Cl}^{-}\left(129 \mathrm{mg} \mathrm{L}^{-1}\right)$. Water $\mathrm{pH}$ was 8.34 . 


\subsection{Experimental procedure and experimental design}

Seven wind tunnel experiments were conducted. They differed in wind speed $(28,11,22,26,25,26$, and $11 \mathrm{~km} \mathrm{~h}^{-1}$ for experiments \#1, \#2, \#3, \#4, \#5, \#6, and $\# 7$, respectively), volumetric moisture of the topsoil layer (9.5 mm of irrigation before soil contamination for experiment \#3 only), type of the water used to dilute virus suspensions (ultrapure water for experiments \#1 to \#5, autoclaved wastewater for experiments \#6 and \#7), and other uncontrolled variables (soil and air temperatures, air relative humidity, solar radiations).

At the beginning of each experiment $(t=0)$, a $0.5 \times 2$ $\mathrm{m}$ plot of bare soil was uniformly moistened with $1 \mathrm{~L}$ of water containing about $10^{+10} \mathrm{gc}$ murine mengoviruses (Fig. 1a). The plot was then covered with a Plexiglas ${ }^{\circledR}$ wind tunnel (cross section $0.24 \mathrm{~m}^{2}$ ) (Fig. 1b). Air was collected at one end through a 2-m-high chimney and expelled at the other end by a fan producing an intunnel wind of velocity $11-30 \mathrm{~km} \mathrm{~h}^{-1}$. Air was sampled through openings in a three-branch system between the tunnel exit and the fan with HX16908 or GR42X25 pumps (ACP Mennecy) (pump flow rate 2.9$\left.4.7 \mathrm{~L} \mathrm{~min}^{-1}\right)$, and viruses were trapped by an AGI-4 impinger (Ace Glass Incorporated, USA) filled with 20 or $40 \mathrm{~mL}$ of trapping solution for collection times shorter or longer than $4 \mathrm{~h}$, respectively (Fig. 1c). The solution was tenfold-diluted PBS for the first two experiments and a culture medium for the other five (9.4 g MEM (Sigma), $14 \mathrm{~mL} 1 \mathrm{M}$ HEPES (Sigma), $20 \mathrm{~mL} \mathrm{Na}^{+}$bicarbonate $7.5 \%, 5 \mathrm{~mL}$ antifungal (Gibco®, Fungizone ${ }^{\circledR}$ ), $10 \mathrm{~mL}$ antibiotic (Gibco ${ }^{\circ}$, penicillin streptomycin), $100 \mu \mathrm{L}$ antifoam B (Sigma), made up to $1 \mathrm{~L}$ with MilliQ water). The impingers were replaced several times over, and their solutions were stored at $-21{ }^{\circ} \mathrm{C}$ for viral quantification. The amount of aerosolized viruses collected by an impinger during a collection period was estimated by using the following equation:

$N_{\mathrm{a}}\left(t_{i+1}\right)-N_{\mathrm{a}}\left(t_{i}\right)=\left(\frac{C\left(t_{i+1}\right) \times V}{Q \times\left(t_{i+1}-t_{i}\right)}\right) \times S \times v \times\left(t_{i+1}-t_{i}\right) \times 1000$

where $t_{i}$ and $t_{i+1}$ are successive times (h) of biocollector changes, $N_{\mathrm{a}}\left(t_{i}\right)$ and $N_{\mathrm{a}}\left(t_{i+1}\right)$ are estimates of $N_{a}\left(t_{i}\right)$ and $N_{\mathrm{a}}\left(t_{i+1}\right)$, respectively, for cumulative amounts of viruses
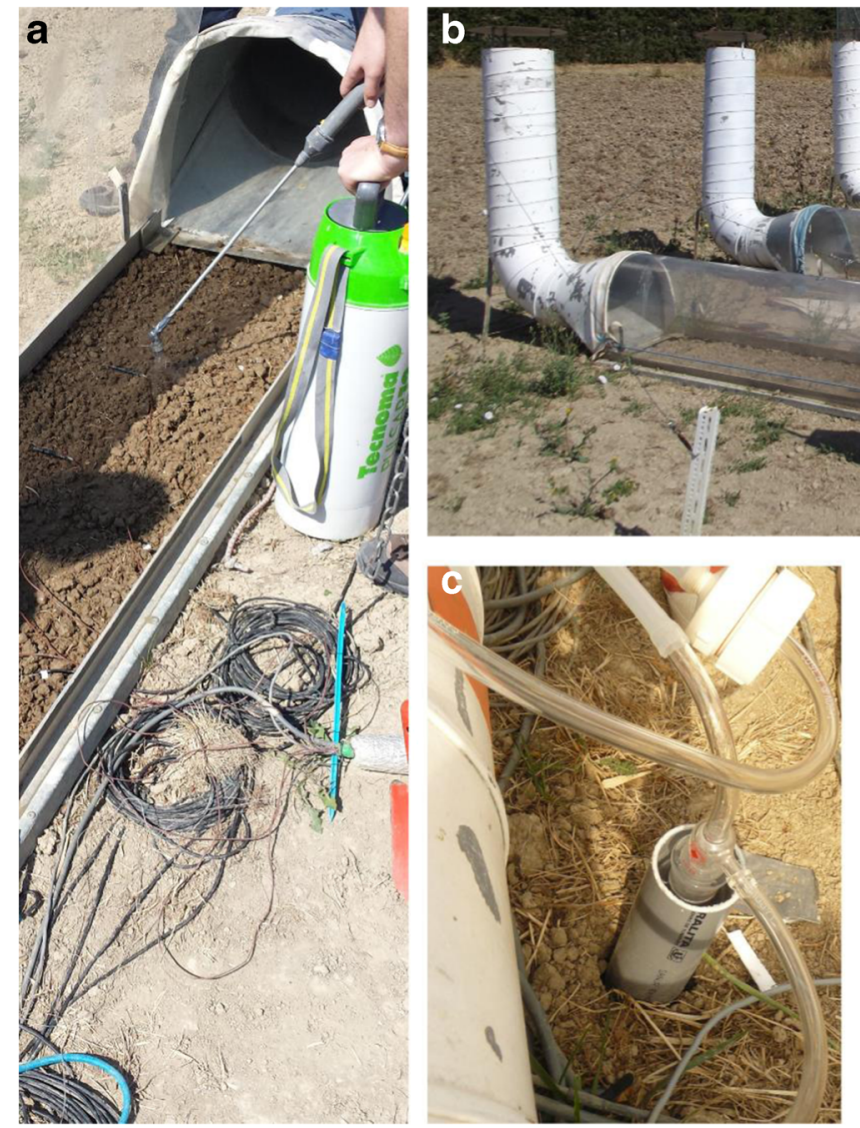
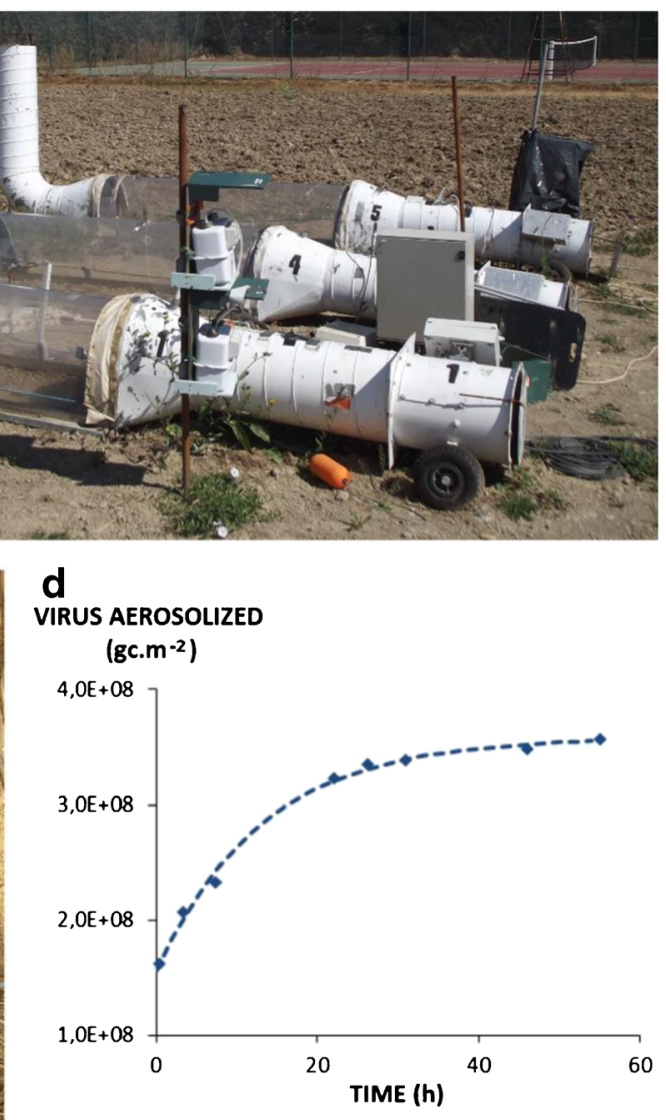

Fig. 1 Characterization of virus aerosolization from a bare soil by using the wind tunnel method. a Soil irrigation with water contaminated with viruses by using a sprayer. $\mathbf{b}$ Wind tunnels in operation for aerosolization assessment, with air being collected at one end through a chimney and expelled at the other end by a fan to simulate wind. $\mathbf{c}$ Virus trapping in the solution of an impinger. d Illustrative example of virus aerosolization kinetics 
aerosolized between the beginning of the experiment $(t=0)$ and times $t_{i}$ and $t_{i+1}$, respectively $\left(\mathrm{gc} \mathrm{m}^{-2}\right), C$ $\left(t_{i+1}\right)$ is estimate of $C\left(t_{i+1}\right)$, the concentration of viruses in the trapping solution $\left(\mathrm{gc} \mathrm{L}^{-1}\right)$ at time $t_{i+1}, V$ is volume of trapping solution remaining at time $t_{i+1}(\mathrm{~L}), Q$ is air flow rate through the impinger $\left(\mathrm{L} \mathrm{h}^{-1}\right), v$ is the wind speed in the wind tunnel $\left(\mathrm{m} \mathrm{h}^{-1}\right)$, and $S$ is the tunnel cross section $\left(\mathrm{m}^{2}\right)$.

At the same time, we also monitored volumetric moisture of the $3-\mathrm{cm}$ topsoil layer by using five EC-10 soil volumetric moisture probes (Decagon Devices Inc.), soil surface temperature by using five T-type thermocouples (copper-constantan) and a PT100 platinum temperature probe giving temperature of the reference junctions, air temperature by using two T-type thermocouples taped to the Plexiglas ${ }^{\circledR}$ tunnel with their sensitive junctions $50 \mathrm{~cm}$ above the soil, and air relative humidity in the tunnel by using a HMP155 probe (HUMICAP®) at the tunnel exit. In-tunnel wind speed was measured with a homemade pulse rate anemometer. A nearby weather station recorded various parameters, including incident global radiation. Each experiment lasted 2-3 days, except for one shorter experiment.

Some laboratory experiments not shown in this paper were performed on three impingers in series containing $10 \%(v / v)$ PBS and a pump driving air downstream of the third impinger to characterize (i) trapping efficiency from the ratio of virus concentrations in the second and third impingers during the first $2 \mathrm{~h}$ and (ii) virus reaerosolization from virus losses after $6 \mathrm{~h}$ in the first impinger. Our results are consistent with those in the review of Verreault et al. (2008), but uncertainties in RNA quantification led to large uncertainties in the proportion of trapped viruses reaerosolized from the first impinger each hour (mean 0.11 and standard deviation 0.07) and in the fraction of aerosolized viruses trapped in the impinger solution (mean 0.75 and standard deviation $0.24)$. The effect of virus trapping and reaerosolization on virus concentration in the impinger was described with the equation:

$\frac{\partial C(t)}{\partial t}=k_{p} \times\left(\frac{A}{V}\right)-k_{h} \times C(t)$

where $k_{p}$ is a trapping coefficient $\left(\mathrm{gc} \mathrm{gc}^{-1}\right)$ varying from 0 to $1, A$ is the amount of viruses flowing through the impinger per unit time $\left(\mathrm{gc} \mathrm{h}^{-1}\right)$, and $k_{h}$ is a coefficient of reaerosolization ranging from 0 to any positive value $\left(\mathrm{h}^{-1}\right)$. For real impingers, Eq. (1) has to be multiplied by the correction factor $f_{\mathrm{c}}$ :

$f_{\mathrm{c}}=\frac{1}{k_{p}} \times \frac{k_{h} \times\left(t_{i+1}-t_{\mathrm{i}}\right)}{1-e^{-k_{h} \times\left(t_{i+1}-t_{\mathrm{i}}\right)}}$
Assuming $k_{p}=0.75$ and $k_{h}=0.11 \mathrm{~h}^{-1}, f_{\mathrm{c}}$ can range from 1.4 to 2.4 for 0.5 to 12 -h collection, respectively. Given the large uncertainties on $k_{\mathrm{p}}$ and $k_{\mathrm{h}}$, we opted for data processing without correction, as widely performed (e.g., Lin et al. 1997; Harstad 1965).

\subsection{Process modeling, uncertainty analysis, and experimental data analysis}

We considered $N_{t}$ viruses $\left(\mathrm{gc} \mathrm{m}^{-2}\right)$ carried to the soil by irrigation, of which $N_{a}(t=\infty)$ could be aerosolized in defined conditions. As long as their probability of aerosolization during a time interval was only dependent on environmental conditions, viruses were assumed to belong to one group, for which aerosolization rate at time $t$ was proportional to the aerosolizable virus quantity on the soil:

$\frac{\partial N_{a}(t)}{\partial t}=+k_{a} \times\left(N_{a}(t=\infty)-N_{a}(t)\right)$

where $N_{a}(t)$ is the cumulative quantity of viruses $\left(\mathrm{gc} \mathrm{m}^{-2}\right)$ aerosolized up to time $t$ and $k_{\mathrm{a}}$ an aerosolization kinetic coefficient $\left(\mathrm{h}^{-1}\right)$. In stable conditions, its integration yielded

$N_{a}(t)=N_{a}(t=\infty) \times\left(1-\exp \left(-k_{a} \times t\right)\right)$

Equation (5) can be extended to $n_{\mathrm{g}}$ groups of mengoviruses that differ according to aggregation to other viruses and/or soil solid particles:

$N_{a}(t)=\sum_{j=1}^{n_{\mathrm{g}}} N_{a, j}(t=\infty) \times\left(1-\exp \left(-k_{a, j} \times t\right)\right)$

where $j$ is the group number. Preliminary analysis led us to consider a volatile group of $N_{i a}$ viruses $\left(\mathrm{gc} \mathrm{m}^{-2}\right)$ that are nearinstantaneously aerosolized and a kinetic group of $N_{a, 2}(t=\infty)$ viruses $\left(\mathrm{gc} \mathrm{m}^{-2}\right)$ more slowly aerosolized, with an aerosolization kinetic coefficient $k_{a, 2}$ :

$N_{a}(t)=N_{i a}+N_{\mathrm{a}, 2}(t=\infty) \times\left(1-\exp \left(-k_{a, 2} \times t\right)\right)$

At any point in time, rate of virus aerosolization can be correctly approximated from the amount of viruses aerosolized during the impinger collection time $\left[t_{i} ; t_{i+1}\right]$, even long times (data not shown):

$$
\begin{aligned}
\frac{\partial N_{a}}{\partial t}\left(\frac{t_{i}+t_{i+1}}{2}\right)= & N_{a}(t=\infty) \times k_{a} \\
& \times \exp \left(-k_{a} \times t\right) \approx \frac{\left(N_{\mathrm{a}}\left(t_{i+1}\right)-N_{\mathrm{a}}\left(t_{i}\right)\right)}{t_{i+1}-t_{i}}
\end{aligned}
$$

We alternatively considered one kinetic group of viruses only and then estimated $N_{a}(t=\infty)$ and $k_{a}$ or one volatile group 
and one kinetic group of viruses and then estimated $N_{i a}$, $N_{a, 2}(t=\infty)$, and $k_{a, 2}$, according to the following two methods:

- Method 1: We fitted the model of cumulative quantities of viruses aerosolized over time $N_{a}(t)$ (Eq. (5) or (7)) to the corresponding experimental amounts $N_{a}(t)$;

- Method 2: First, we fitted the model of $\partial N_{a}(t) / \partial t$ (Eq. (8)) to the aerosolization rates estimated over the periods of use of an impinger except the first 30-min period to estimate either $N_{a}(t=\infty)$ and $k_{a}$ or $N_{a, 2}(t=\infty)$ and $k_{a, 2}$. Then, when simultaneously considering one volatile group and one kinetic group of viruses, we estimated the size of the volatile group $N_{i a}$ by splitting virus aerosolization during the first $30 \mathrm{~min}$ into kinetic and near-instantaneous aerosolizations.

Fittings were performed by minimizing the sum of squared deviations between the logarithms of simulations and numerical experiments. In method 2 , we considered linear variations of the logarithm of $\partial N_{a}(t) / \partial t$ with $t$ (slope $-k_{a} ; y$-intercept $\ln \left(k_{a} \times N_{a}(t=\infty)\right)$.

To compare the methods, we generated 100 numerical experiments corresponding to realizations of one experiment with only one kinetic group characterized by $N_{a}(t=\infty)=10^{8} \mathrm{gc} \mathrm{m}^{-2}$ and $k_{a}=0.07 \mathrm{~h}^{-1}$ that were in the range of values estimated from actual wind tunnel experiments and at each date $t_{i+1}$ three replicates of RTqPCR measurements $C\left(t_{i+1}\right)$ following a log-normal distribution, the standard deviation of their natural logarithm $\sigma_{a-\ln }$ being constant and their mean obeying the following equation:

$E\left(\log \left(C\left(t_{i+1}\right)\right)\right)=\log \left(C\left(t_{i+1}\right)\right)-\frac{\sigma_{a-\ln }^{2}}{2}$

$\sigma_{a-\ln }=0.81$ enabled us to simulate a distribution of standard deviation estimates similar to the observed distribution, but with less dispersion (data not shown). The standard deviations of $N_{a}(t=\infty)$ and $k_{a}$ derived from method 2 were 2.3 and 2.6 times lower than those derived from method 1, respectively. According to method 2, most of the $N_{a}(t=\infty)$ estimates were between 0.5 and 2 times the actual value $N_{a}(t=\infty)$ and most of the $k_{a}$ estimates were between 0.7 and 1.4 times the actual value $k_{a}$.

The values of $N_{i a}, N_{a, 2}(t=\infty)$, and $k_{a, 2}$ estimated by method 2 from actual experiments were analyzed relative to wind speed, solar radiation, air temperature and relative humidity, soil surface temperature and moisture, and irrigation water quality. The trends between $N_{a, 2}(t=\infty)$ estimates from method 2 and environmental variables prompted us to simultaneously fit simulations to all the experiments considering seven $N_{i a}$ values, seven $k_{a, 2}$ values, and a single relationship between $N_{a, 2}(t=\infty)$ and wind speed, soil surface temperature, and irrigation water quality:

$N_{a, 2}(t=\infty)=\left(a \times v_{\text {wind }}^{2} \times \exp (-b \times T)\right)+c \times I$

where $v$ and $T$ are mean wind speed $\left(\mathrm{km} \mathrm{h}^{-1}\right)$ and temperature $\left({ }^{\circ} \mathrm{C}\right)$ throughout the experiment, $I$ is an index of irrigation water quality ( 0 for pure water; 1 for wastewater), and $a, b$, and $c$ are coefficients.

\section{Results and discussion}

First, we managed to produce repeatable experiments: Initial contamination level appeared identical for each wind tunnel experiment. Average amount of viruses received by the soil $N_{v-t}$ was estimated at $1.46 \times 10^{10}$ $\mathrm{gc} \mathrm{m}^{-2}$. For each experiment, viral quantifications in the suspension applied to the soil were performed in three to four replicates with tenfold dilution of samples to be analyzed to check for possible PCR inhibition. The measurements showed no dilution dependence, in particular for wind tunnel experiments \#6 and \#7 in which viruses were supplied with wastewater containing various compounds that could have potentially interfered with RT-qPCR measurements. Second, aerosolization is significant: Without correcting experimental data by the $f_{\mathrm{c}}$ correction factor, the cumulative amount of viruses aerosolized at the end of the experiments corresponded to $23.1,7.5,2.4,0.8,1.7,5.7$, and $1.7 \%$ of the total amount of viruses initially carried to the soil for experiments \#1, \#2, \#3, \#4, \#5, \#6, and \#7, respectively (Fig. 2). Third, most aerosolization happens very early: 29$67 \%$ of aerosolized viruses were aerosolized during the first $30 \mathrm{~min}$, suggesting marked early aerosolization.

Detailed analysis of experiment \#3 (Fig. 3) showed that a simple model without instantaneous aerosolization was insufficient. Fitting models by using just one group of kinetic viruses (Eqs. (2) and (3)) and estimating $N_{a}(t=\infty)$ and $k_{a}$ for this group only by method 1 yielded bias against observations (Fig. 3a). It is thus necessary to account for at least two groups, as a three-parameter model is fittable (Eq. (5)). However, ignoring the 0-30-min period after virus contamination, simulations were fitted to all other observed fluxes by accounting for just one group of kinetic viruses (Fig. 3b). Fluctuations of the natural $\operatorname{logs}$ around the regression line were of the same order of magnitude as observed for numerical experiments, despite variations in soil surface temperature and 0-3-cm topsoil layer moisture (Fig. 3c) and in wind speed (Fig. 3d). Second, whatever the method, estimated sizes of 
Fig. 2 Observed (dots) and simulated (lines) cumulative amounts of virus aerosolized over time for experiments \#1 to \#7. (Missing values (empty dots) were estimated from preceding and following values). Wind speed 28, 11, 22, 26, 25, 26, and $11 \mathrm{~km} \mathrm{~h}^{-1}$ for experiments \#1 to $\# 7$, respectively; mean soil surface temperature $23,26,24$, $24,28,22$, and $25^{\circ} \mathrm{C}$ for experiments \#1 to \#7, respectively)>

\section{$\hat{N}_{\mathrm{a}}(\mathrm{t})\left(\mathrm{gc} \cdot \mathrm{m}^{-2}\right)$}

$4,0 \mathrm{E}+09$
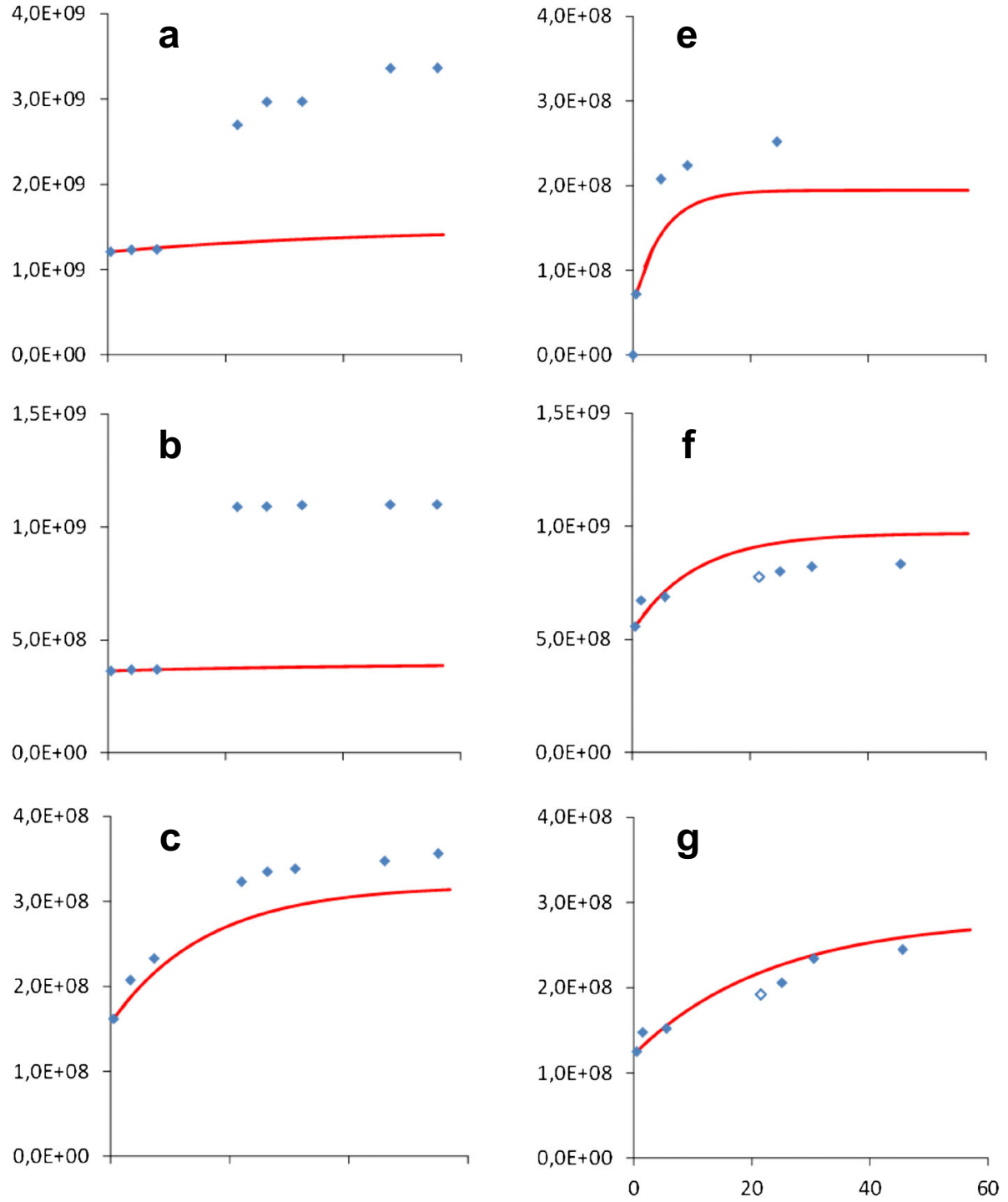

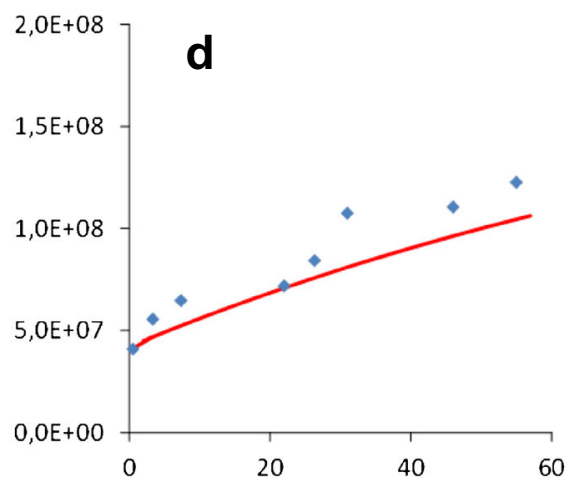

TIME (h) 
Fig. 3 Wind tunnel experiment \#3 plotted with a cumulated amount of aerosolized virus, $\mathbf{b}$ instantaneous virus aerosolized flux, $\mathbf{c} 0-3$-cm soil moisture and soil surface temperature, and $\mathbf{d}$ wind speed and global solar radiation>
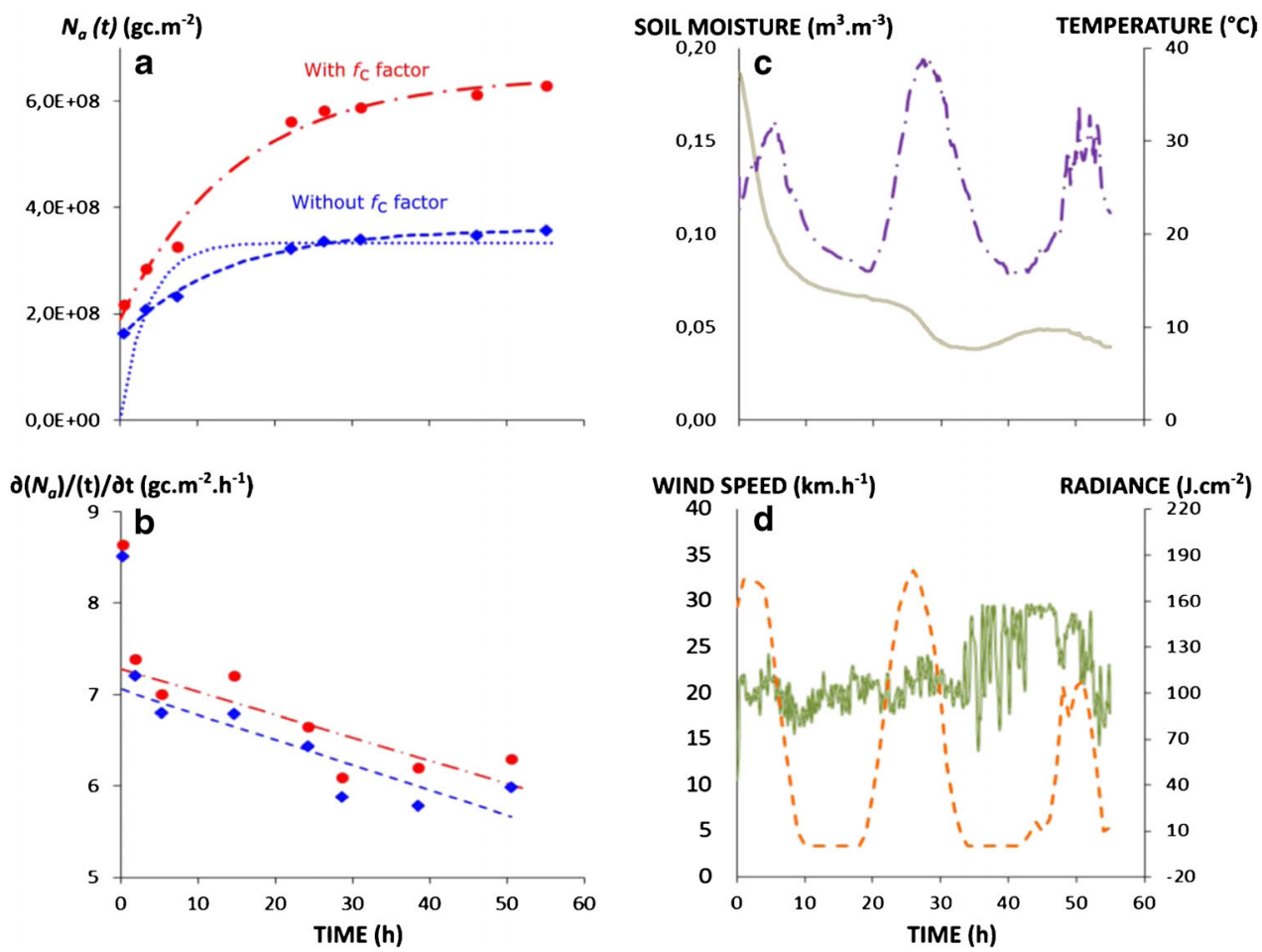

aerosolizable virus quantities were similar to their experimental counterparts (Table 1 ), i.e., $N_{a}(t=\infty)$ estimated by method 1 accounting only for one kinetic group, the sums of $N_{i a}$ and $N_{a, 2}(t=\infty)$ estimated by method 1 or 2 , when accounting for one near-instantaneous group and one kinetic group, together with the sum of $N_{i a}$ and $N_{a, 2}(t=\infty)$ estimated by the overall fit of simulations to all wind tunnel experimental data, were all close to the experimental cumulative amount of aerosolized viruses $\left(3.6 \times 10^{8}\right.$ $\mathrm{gc} \mathrm{m}^{-2}$ after $55 \mathrm{~h}$ ). In addition, $k_{a}$ estimates were similar to each other when distinguishing two viral groups but higher when considering only one kinetic group of viruses. Third, when considering two virus groups and method 2, correcting for impinger data bias by factor $f_{\mathrm{c}}$ does not change the $k_{a}$ estimates $(0.058$ instead of 0.064$)$, but $N_{i a}$ and $N_{a, 2}$ and $N_{i a}$ and $N_{a, 2}(t=\infty)$ have to be multiplied by 1.32 and 1.84 , respectively.

If we look at all the experiments together, similar results were found. First, methods 1 and 2 fitted well to experimental data (data not shown), but method 2 was more robust to experimental errors. The four estimates obtained by fitting models to experiments were close to the experimental cumulative quantities of aerosolized viruses, except for experiments $\# 1$ and \#2 (Table 1). Note that in experiments \#1 and \#2, virus aerosolizations between 8.3 and $22 \mathrm{~h}$ corresponded to the use of a single impinger and were almost certainly greatly overestimated, leading to a far greater overestimation of $N_{a, 2}(t=\infty)$ with method 1 than method 2 (Table 1). Second, when considering two virus groups and method 2, correcting impinger data by the $f_{\mathrm{c}}$ factor leads to little change in $k_{a}$ estimates ( 0.6 to 0.9 times the uncorrected value), whereas of $N_{i a}$ and $N_{a, 2}(t=\infty)$, estimates were multiplied by $1.1-1.3$ and 1.62.8 , respectively. In addition, considering the seven wind tunnel experiments, Eq. (10) was well fitted to the seven $N_{a, 2}$ $(t=\infty)$ estimates from method 2 by estimating the three coefficients $a, b$, and $c$ :

$$
\begin{aligned}
& N_{a, 2}(t=\infty) \\
& =\left(7.1510^{+6} \times v_{\text {wind }}^{2} \times \exp (-0.123 \times T)\right) \\
& +1.0910^{+8} \times I
\end{aligned}
$$

However, a similar model could not be fitted for $N_{i a}$ due to the large errors on the experimental estimates. The same happened for $k_{a}$, probably due to insufficient inter-experiment variability.

Fitting model 2 of virus aerosolization rates simultaneously to all experimental aerosolization rates for the seven wind tunnel experiments by substituting $N_{a}$, ${ }_{2}(t=\infty)$ in Eq. (7) by Eq. (10) led, after eliminating the two outliers in experiments \#1 and \#2, to a residual standard deviation of 1.25 on the natural logarithms (Fig. 4), i.e., a value approaching the residual standard deviation of the natural logarithms of viral RT-qPCR quantifications. Equation (10) can then be rewritten with the values for coefficients $a, b$, and $c$ which are near those already 


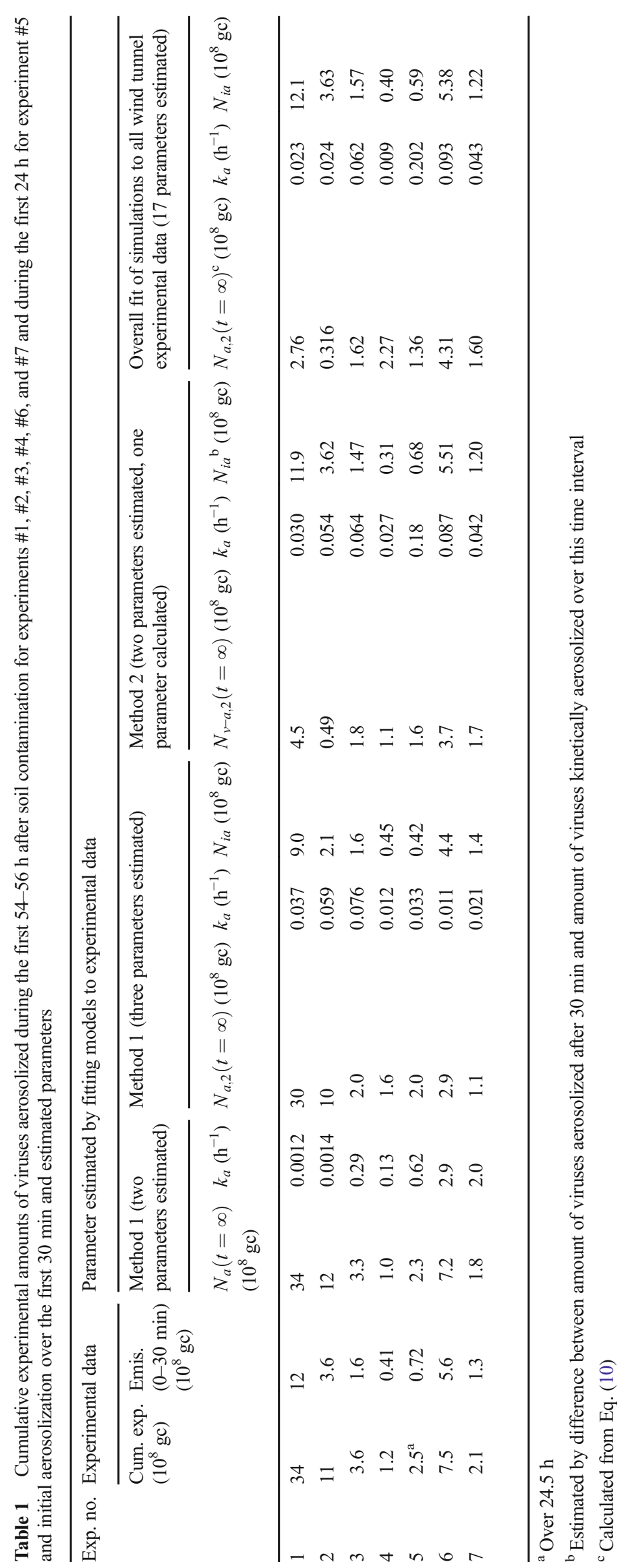




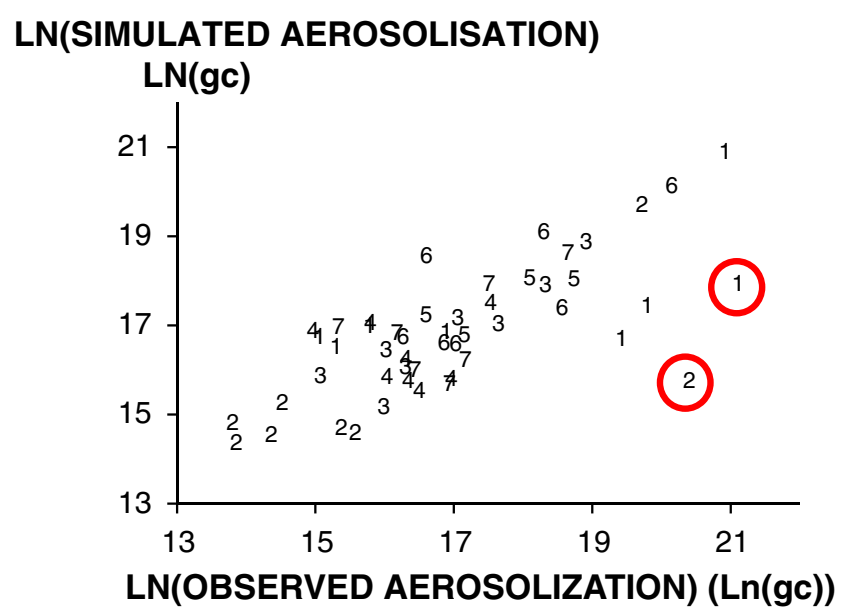

Fig. 4 Relationship between natural logarithms of observed and simulated emissions during time intervals corresponding to the use of one same impinger for all seven wind tunnel experiments. Dots surrounded by a red circle correspond to values ignored when fitting models to experimental data>

proposed in Eq. (11).

$$
\begin{aligned}
& N_{a, 2}(t=\infty) \\
& =\left(5.5310^{+6} \times v_{\text {wind }}^{2} \times \exp (-0.117 \times T)\right) \\
& \quad+1.2610^{+8} \times I
\end{aligned}
$$

Applying the correction factor $f_{\mathrm{c}}$ as described above gave similar trends: no great change in $k_{a}$ estimate (0.73-1.0 times its value without factoring in $\left.f_{\mathrm{c}}\right)$ but $N_{i a}$ and $N_{a, 2}(t=\infty)$ multiplied by $1.2-1.3$ and $1.8-2.1$, respectively.

Observations showed the need to distinguish viruses by their degree of attachment to the soil surface. Distinguishing a volatile group of viruses aerosolized near instantaneously at the beginning of the experiments from a kinetic group of viruses aerosolized more gradually proved sufficient to fit experimental observations. Variations in the sizes of these two groups and in the kinetic constant of aerosolization of the kinetic group with environmental context could probably be explained by variations in the forces involved in virus adhesion to other viruses and/or soil particles (Dika et al. 2013; Cao et al. 2010), cohesion between soil particles, and snatching caused by wind.

While the effects of wind and water composition on aerosolization were expected, the effect of temperature was less expected. Indeed, the effect of water composition may have resulted from the presence of soluble organic compounds in wastewater that could then compete with viruses for adsorption on soil solids (Cao et al. 2010), although the overall effect of wastewater compounds is almost certainly the resultant of opposing effects. Conversely, we did not observe an increase of aerosolization with temperature that could have resulted from the concomitant increase in thermal agitation; several mechanisms may be involved, including variations in hydrophilic/hydrophobic-type forces (Syngouna and Chrysikopoulos 2010), as hydrophobic forces are essential in virus adsorption (Dika et al. 2013) and temperature-driven changes in the exposed charge moiety (Lee et al. 2015). Surprisingly, we did not note any effect of soil water content on virus adhesion to soil surface, whereas several studies have addressed virus-water-inert solid surface interactions. Here, we measured soil moistures in the $0-3-\mathrm{cm}$ topsoil layer, whereas it would be necessary to measure soil moisture at the soil-air interface.

\section{Conclusions}

To our knowledge, this is the first study to confirm that enteric viruses carried to soil by irrigation with contaminated water, e.g., wastewater, can subsequently become aerosolized during windy spells, even at moderate wind speeds. Beyond this qualitative result, simultaneously fitting all the data from all seven wind tunnel experiments showed that $1-15 \%$ of inborne viruses were aerosolized, of which 11-89\% were aerosolized in the first $0.5 \mathrm{~h}$. Our analysis shows the need to distinguish viruses by their degree of attachment to the soil surface. Distinguishing a group of viruses aerosolized near instantaneously at the beginning of the experiments from a group of viruses aerosolized more gradually proved sufficient to fit all experimental observations. The range of kinetic coefficients of aerosolization of the gradually aerosolized group accounted for $90 \%$ of viruses of this group aerosolized after 0.5-10.6 days. The size of this group increases with wind speed, decreases with soil warming, and is bigger when using wastewater than pure water. Combined with knowledge on virus exchange from respiratory to gastroenteric tracts and virus inactivation in air, we anticipate our model to help policymakers to refine regulations and standards governing wastewater reuse in irrigation.

Acknowledgments This work received funding via the AgAdapt project under the French ANR [National Research Agency] program, from the "Devenir des virus pathogènes de l'homme dans l'environnement" project under the INRA [National Agronomics Research Institute] program, from the "Evaluation des risques liés aux virus entériques de l'homme émis dans l'atmosphère à proximité des sites de traitement d'eaux usées ou de réutilisation en irrigation" project under the French National EC2CO BIohefect/MicrobiEn program, and from the EVASION project under the ECCOREV program. The authors thank the ProvenceAlpes-Côte-d'Azur Regional Council and SUEZ-Environment for support through G. Girardin's PhD grant. We also thank A. Bosch (University of Barcelona, Spain) for kindly providing the MC0 strain of murine mengovirus and BGMK cells, B. Loubet (INRA, Grignon, France) for kindly lending us access to the wind tunnels, D. Renard and C. Ball for technical assistance, and Glen McCulley for English-proofing the manuscript. 
Open Access This article is distributed under the terms of the Creative Commons Attribution 4.0 International License (http:// creativecommons.org/licenses/by/4.0/), which permits use, duplication, adaptation, distribution and reproduction in any medium or format, as long as you give appropriate credit to the original author(s) and the source, provide a link to the Creative Commons license and indicate if changes were made.

\section{References}

C.A.C. (Codex Alimentarius Commission) (2012) Guidelines on the application of general principles of food hygiene to the control of viruses in food

Cao H, Tsai FTC, Rusch KA (2010) Salinity and soluble organic matter on virus sorption in sand and soil columns. Groundwater 48:42-52. doi:10.1111/j.1745-6584.2009.00645.x

Dart A, Thornburg J (2008) Collection efficiencies of bioaerosol impingers for virus-containing aerosols. Atmos Environ 42:828832. doi:10.1016/j.atmosenv.2007.11.003

DiCaprio E, Culbertson D, Li J (2015) Evidence of the internalization of animal caliciviruses via the root of growing strawberry plants and dissemination to the fruit. Appl Environ Microbiol 81:2727-2734. doi:10.1128/AEM.03867-14

Dika C, Ly-Chatain MH, Francius G, Duval JFL, Gantzer C (2013) NonDLVO adhesion of F-specific RNA bacteriophages to abiotic surfaces: importance of surface roughness, hydrophobic and electrostatic interactions. Colloid Surf A: Physicochem Eng Aspects 435: 178-187. doi:10.1016/j.colsurfa.2013.02.045

Esseili MA, Wang Q, Saif LJ (2012) Binding of human GII. 4 norovirus virus-like particles to carbohydrates of romaine lettuce leaf cell wall materials. Appl Environ Microbiol 78:786-794

Gerba CP (1999) Virus survival and transplant in groundwater (volume 24). J Ind Microbiol Biot 22:247-251. doi:10.1128/AEM.07081-11

Harstad JB (1965) Sampling submicron T1 bacteriophage aerosols. Appl Microbiol 13:899-908

Jiménez B, Drechsel P, Koné D, Bahri A, Raschid-Sally L, Qadir M (2010) Wastewater, sludge and excreta use in developing countries: an overview. In: Drechsel P, Scott CA, Raschid-Sally L, Redwood $\mathrm{M}$, Bahri A (eds) Wastewater irrigation and health assessing and mitigating risk in low-income countries. Earthscan, London, pp. 3-27

Lee MFX, Chan ES, Tam KC, Tey BT (2015) Thermo-responsive adsorbent for size-selective protein adsorption. J Chromatogr A 1394:7180. doi:10.1016/j.chroma.2015.03.034

Lin X, Willeke K, Ulevicius V, Grinshpun SA (1997) Effect of sampling time on the collection efficiency of all-glass impingers. Am Ind Hyg Ass J 58:480-488. doi:10.1080/15428119791012577

Loubet B, Cellier P, Flura D, Genermont S (1999) An evaluation of the wind-tunnel technique for estimating ammonia volatilization from land: part 1. Analysis and improvement of accuracy. J Agric Engng Res 72:71-81. doi:10.1006/jaer.1998.0348
Mara DD, Sleigh PA, Blumenthal UJ, Carr R (2007) Health risks in wastewater irrigation: comparing estimates from quantitative microbial risk analyses and epidemiological studies. J Water Health 5:3950. doi:10.2166/wh.2006.055

Martin LR, Duke GM, Osorio JE, Hall DJ, Palmenberg AC (1996) Mutational analysis of the mengovirus poly $(C)$ tract and surrounding heteropolymeric sequences. J Virol 70:2027-2031

Masclaux FG, Hotz P, Gashi D, Savova-Bianchi D, Oppliger A (2014) Assessment of airborne virus contamination in wastewater treatment plants. Environ Res 133:260-265. doi:10.1016/j.envres.2014.06. 002

Mattison K, Bidawid S (2009) Analytical methods for food and environmental viruses. Food Environ Virol 1:107-122. doi:10.1007/ s12560-009-9017-6

Nazaroff WW (2011) Norovirus, gastroenteritis, and indoor environmental quality. Indoor Air 21(5):353-356. doi:10.1111/j.1600-0668. 2011.00735.x

Pachepsky Y, Shelton DR, McLain JET, Patel J, Mandrell RE (2011) Irrigation as a source of pathogenic microorganisms in produce: a review. Adv Agron 113:73-138. doi:10.1016/B978-0-12-386473-4. 00007-5

Pinto RM, Costafreda MI, Bosch A (2009) Risk assessment in shellfishborne outbreaks of hepatitis a. Appl Environ Microbiol 75:7350 7355. doi:10.1128/AEM.01177-09

Prevost B, Lucas FS, Goncalves A, Richard F, Moulin L, Wurtzer S (2015) Large scale survey of enteric viruses in river and waste water underlines the health status of the local population. Environ Int 79: 42-50. doi:10.1016/j.envint.2015.03.004

Rodríguez-Lázaro D, Cook N, Ruggeri FM, Sellwood J, Nasser A, Nascimento MSJ, D’Agostino M, Santos R, Saiz JC, Rzeżutka A, Bosch A, Gironés R, Carducci A, Muscillo M, Kovač K, DiezValcarce $\mathrm{M}$, Vantarakis A, von Bonsdorff $\mathrm{CH}$, de Roda Husman AM, Hernández M, van der Poel WHM (2012) Virus hazards from food, water and other contaminated environments. FEMS Microbiol Rev 36:786-814. doi:10.1111/j.1574-6976.2011.00306.x

Sano D, Ohta T, Nakamura A, Nakagomi T, Nakagomi O, Okabe S (2015) Culture-independent evaluation of nonenveloped-virus infectivity reduced by free-chlorine disinfection. Appl Environ Microbiol 81:2819-2826. doi:10.1128/AEM.03802-14

Syngouna VI, Chrysikopoulos CV (2010) Interaction between viruses and clays in static and dynamic batch systems. Environ Sci Technol 44:4539-4544. doi:10.1021/es100107a

Teltsch B, Katzenelson E (1978) Airborne enteric bacteria and viruses from spray irrigation with wastewater. Appl Environ Microbiol 35: 290-296

Van der Bruggen, B (2010) Chapter 3: the global water recycling situation. In: Escobar I, Schäfer A (eds) sustainable water for the future: water recycling versus desalination, pp 41-62

Verreault D, Moineau S, Duchaine C (2008) Methods for sampling of airborne viruses. Microbiol Mol Biol Rev 72:413-444. doi:10.1128/ MMBR.00002-08 